\title{
Chest Wall Disorder
}

National Cancer Institute

\section{Source}

National Cancer Institute. Chest Wall Disorder. NCI Thesaurus. Code C35745.

A non-neoplastic or neoplastic disorder that affects the structures of the chest wall.

Representative examples include infection, chest wall lipoma, and chest wall lymphoma. 